\title{
The history of analgesia in burns
}

\author{
JoHN F. MURRAY \\ F.F.A., R.C.S. \\ Queen Victoria Hospital, East Grinstead
}

SiNCE man first discovered fire, burn injuries have presumably occurred, and in the earliest literature we find evidence of the treatment of burns. In sharp contrast to our time no distinction was made initially between the cure of the lesion and the relief of pain.

An ancient Egyptian medico-religious instruction speaks of the god Horus being burned and calling upon Isis, who said: "Come with me my sister Nephthys, walk with me. I know how to extinguish the fire with my milk, with the wholesome fluid that is between my legs.' Whether any important lesson for modern therapeutics lies hidden in this quotation must remain, I'm afraid, a matter for speculation. Plant gums are also mentioned as being of value in the therapy of burns.

Little change or advance in treatment occurred until the Renaissance in the sixteenth century. Gunpowder was being used on a wide scale, leading to an increasing incidence of severe burning and to the rise of a new breed of practical military surgeons to treat the condition. The most notable of these was Ambroise Paré, who had an experimental mind and ample material upon which to practise. In his Apologia and Treatise he writes of the kitchen boy of the Marquis de Montjou, who had fallen in burning oil, and there being none of the usual refrigerating medicine available, he took the advice of an old country woman to lay upon the burned area, onions and a little salt. Next day he found that the treated areas had not developed blisters, whereas the untreated areas had. This therapy was in use up to the last century.

Paré also tells of three soldiers found standing against a wall after a French assault on Turin, burned from head to foot by a gunpowder explosion with the remnants of their clothes still smouldering upon them. An old soldier asked if Paré could cure them, and being told no, gently slit their throats. Paré called him a villain, to which he replied that he prayed to God that he himself would be treated likewise in the same circumstances. Paré also suggested the use of a digestive of yolk of eggs, oil of roses, and turpentine which gave superior results to the then commonly used boiling elder oil. He was gratified to find that his remedy resembled that of a Turin surgeon famous for the treatment of burns, whose acquaintance he had assiduously cultivated. This remedy consisted of young whelps boiled in oil of lilies and earthworms prepared in turpentine.

Remedies such as these were used in the succeeding years with a tendency to accompany them by blood letting and purging. The great physician Boerhaave (1668-1738) of Leyden, when burned badly about the face underwent this treatment on three occasions in 8 days, after which he was again surprisingly in good health.

Once again it was a military surgeon, Baron Larrey, surgeon to the Emperor Napoleon I, who brought about dramatic changes in the treatment of burns (Dible, 1970). He abandoned the use of the then popular Goulard water (a crude solution of lead acetate) and used instead fine linen which had been soaked in saffron pomade. The latter apparently gave considerable relief of pain. Larrey also realized the importance of a high intake of fluids and food and of maintaining the patient's strength, in marked contrast to the bleeding and purging then still in vogue.

Baron Larrey's ideas had considerable influence on British practice during the first half of the nineteenth century. In the New London Surgical Handbook of 1836 his methods are mentioned, but so are more violent treatments such as the painting of the wound with vinegar until the pain abated. Vinegar is of value, we now know, in combating pyocyaneus infection. In the same book mention was also made of the use of opium and of opium and wine in the treatment of pain caused by burns. Sir George Ballingall, surgeon to the British Army, writing in 1833, whilst giving an admirable account of the natural history of burns continued to recommend bleeding and purging. A simple dressing of dry cotton wool was introduced from America in 1828. Syme, working at the world's first burns hospital in Edinburgh, emphasized that this dressing should be applied with firm pressure.

It is of interest at this point to examine the progress which was to be made in the treatment of burns in the next 100 years, the figures being taken 


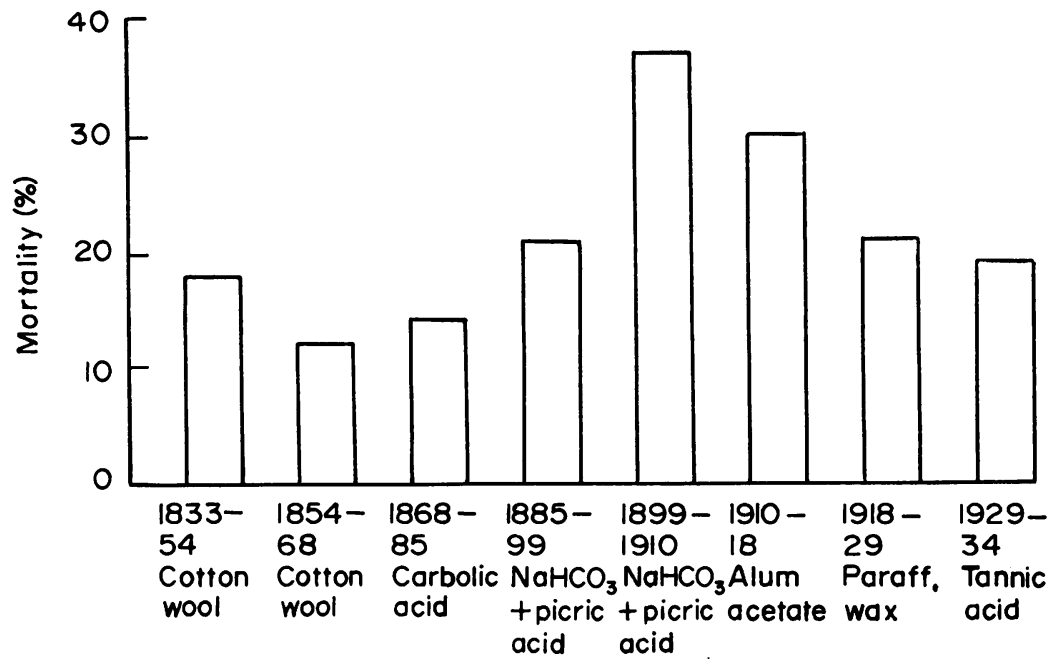

FIG. 1. Mortality from burns and scalds (Glasgow Royal Infirmary).

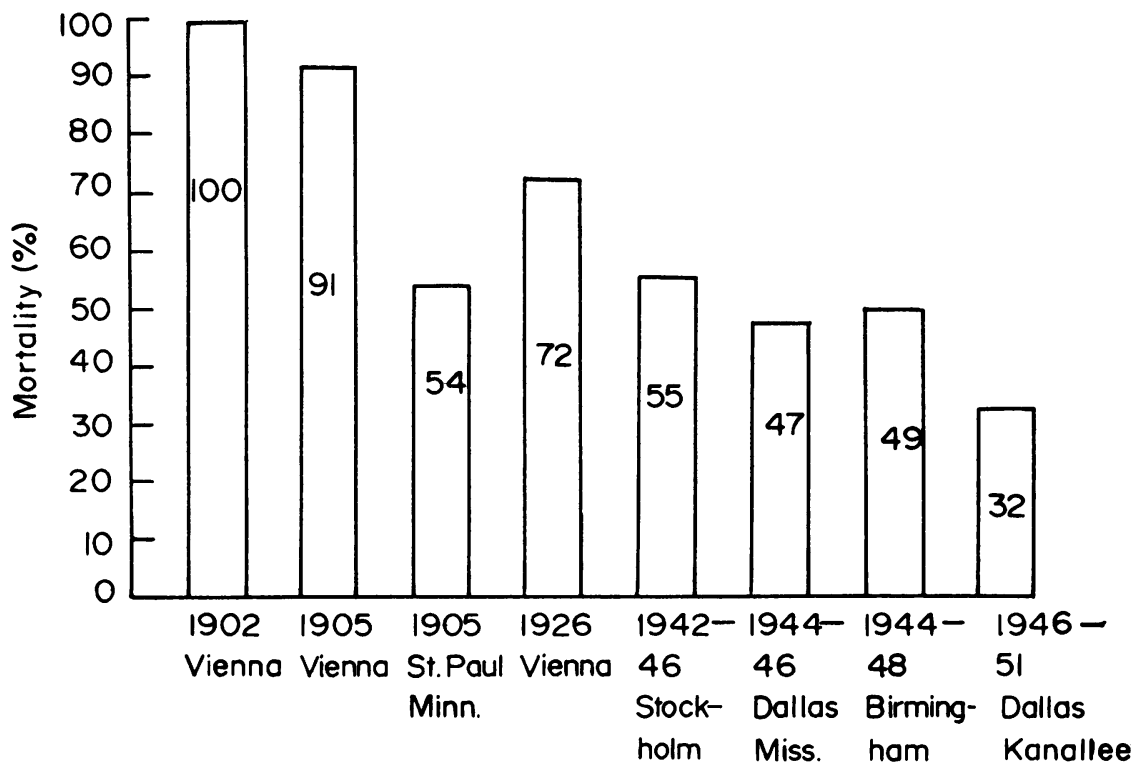

FIG. 2. Mortality from burns involving more than $25 \%$ of the body surface (patients under 61 years).

from Dunbar in the Glasgow Medical Journal of 1934 (Fig. 1).

If we deal with the more specific problem of the treatment of burns involving more than $25 \%$ of body surface, the results since 1900 are again of considerable interest (Fig. 2). Probit analysis of these three figures shows no significant difference in results compared with those of Sneve in 1905.

The above figures showed that the mortality from burns involving more than $25 \%$ of the body surface fell from $100 \%$ to $75 \%$ with the administration of rectal or subcutaneous fluids, and to $42 \%$ with intravenous fluids.

The use of anaesthesia in the dressing of burn wounds is first mentioned in a Manual of Nursing published in 1900 (Humphrey, 1900), in which is stated that the surgeon may give chloroform if necessary for painful dressing. A Royal Army Medical 
Corps Training Manual (HMSO) for 1911, however, made no mention of the necessity for pain relief.

The 1914-18 war saw an increase in casualties and some accompanying advances in the treatment of burns. Complete occlusive dressings were the rule. These contained mainly paraffin wax which was applied hot, and was thus capable of further damaging the tissues. Intravenous fluid therapy was, however, contributing to a higher survival rate despite the local treatment used.

Tannic acid, which was said to give considerable relief of pain, was popularized in 1922 by Davidson, and its use was continued, despite criticism, until the 1939-45 war. The number of burns casualties increased considerably during that war, and the ill effects of the tanning treatment became evident. Nonetheless, we find Sir Cecil Wakely, in 1944, advocating the use of tannic acid for burns. He also advocated the use of morphine ad libitum, 'Morphine will never kill a patient in severe pain'. A dose of up to 2 grains $(130 \mathrm{mg})$ intramuscularly was suggested for shocked patients. Such advice would now be frowned upon.

Treatment by exposure methods and the use of constant temperature baths to relieve pain during the removal of eschar were increasingly mentioned during the war years. Short acting barbiturates were sometimes used for dressings as was full nitrous oxide and ether anaesthesia, but it was observed that repeated general anaesthesia was detrimental to the patient's condition, and its use was advised against in the Field Surgery Pocket Book (War Office publication, London) in June 1944. The use of cyclopropane anaesthesia, which made rapid recovery from the anaesthetic possible, was a considerable improvement. In contrast Clarkson \& Lawrie in 1946 warned against the use of intermittent intravenous thiopentone which had, in their experience, been associated with prolonged coma in several patients.

It is interesting to note that at the end of the war the German Army still employed tannic acid, which was applied under primitive general anaesthesia. Dressings were performed under analgesia provided by a mixture of oxycodone, ephedrine and scopolamine, given by injection.

After the war, exposure treatment continued to be popular. The need to remove the eschar and prepare surfaces for grafting brought increased references to the use of anaesthesia. Allen \& Slocum described, in 1952, the experience of their unit in Galveston, Texas, in a report which exemplifies the prevailing trends. Heavy barbiturate sedation was used initially, but had been unsatisfactory due to the frequent occurrence of delirium, and more rarely of coma, which culminated in one case in death due to drug overdosage in 1946. Thereafter, full general anaesthesia was employed, but the prolonged pre- and post-operative starvation proved deleterious. The result was a reduction in food and fluid intake by the patients to the detriment of their general condition. The administration of a 50:50 mixture of nitrous oxide and oxygen, to which cyclopropane was added during particularly painful episodes, was found to be a marked improvement. The authors stressed the importance of commencing the administration of analgesia before painful stimuli were encountered, in order to maintain the morale and confidence of the patients.

During this period, pre-occupation with factors other than those directly concerned with the burn itself became evident. As a result of improvements in therapy, even very severely burned patients were expected to survive over 2 weeks. The maintenance of the patient's nutritional intake and his morale had been recognized as contributory to his prospect of survival. In addition, the morale of nursing and medical staff was recognized as being of importance in supporting the patient and gaining his co-operation at a crucial stage in his illness. Woodward, in 1959 , found that $81 \%$ of burned children showed evidence of psychological disturbance after hospitalization, as compared with $17 \%$ of a control group of children. Harbauer, in 1963, reported similar findings. The absence of pain during dressing procedures was clearly an important factor in the prevention of these complications, and many agents and methods of administration were advocated as suitable for this purpose.

The use of opiates alone proved unsatisfactory in the dressing of burns, whether because of the prolonged sedation they produced, the inadequacy of analgesia, or the danger of addiction, and various authors reported on the use of inhalational agents. Trichlorethylene was used in a large number of centres and its use was reported on by Gleadow in 1945, Thompson, Drewer \& Grounds in 1949 and Howie in 1970. It is stated to have the advantages of quiet induction and awakening, negligible sideeffects, and analgesia prolonged after the patient had awoken. Feeding could be commenced within a short period of the administration being terminated; within half an hour in some cases.

Allen \& Slocum, writing in 1952, stated that they had found the administration of thiopentone intravenously, or if necessary into the bone marrow, followed by inhalation of nitrous oxide and oxygen, satisfactory. They stressed the need for a rapid recovery and the prevention of vomiting. This had occurred in their experience, after administration of morphine to burned patients, thus further reducing the fluid intake in those patients.

Visser \& Tarrow, in 1959, described their experience in the use of halothane for the repeated dressing of burns. They found no evidence of liver 
damage in any of their series. Latterly methoxyfluorane, which has been used in this hospital and other centres, was reported by Dr Packer and Dr Titel in 1969.

However, intravenous agents cannot be ignored. Gordon, in 1959, reported the use of a $1 \%$ solution of procaine in dextrose saline, administered by intravenous infusion, up to $1 \mathrm{~g}$ of procaine being used in all. There was no systemic upset and analgesia was present for up to $12 \mathrm{hr}$ after the administration had ceased. Black, in 1943, used small doses of morphine intravenously to which cyclopropane or nitrous oxide/oxygen, by inhalation, were added when necessary. Neuroleptanalgesia has also been used. A series of seventy-six dressings in twenty-four patients was reported by Smith \& Hollis from this hospital in 1966. There was satisfactory analgesia on seventy occasions, but a tendency to prolonged drowsiness led to the abandonment of this technique in favour of methoxyflurane analgesia at this hospital. Ketamine, administered intravenously or intramuscularly, was reported by Cohen in 1970 as being satisfactory. He stressed its value in patients in whom maintenance of a clear airway would have been difficult, had conventional anaesthetic agents been used.

Hypnosis must lastly be mentioned. It has been used both for pain relief and to reduce the significance of pain to the patient. Bernstein, in 1963, successfully treated particularly disturbed patients who were refusing to eat or to co-operate, and in one case the administration of analgesics which had previously been necessary in large doses, was eliminated. Bernstein also emphasized the value of a psychiatrist in giving both patient and staff an insight into their own feelings and reactions towards burn injuries, thereby eliminating emotional barriers on both sides, which would otherwise be detrimental to the patient's progress towards recovery.

Here indeed is the essence of the problem. Analgesia provides but one way of reducing the overall stress to which a burned patient is subjected. The elimination of all, or a part of the pain accompanying this illness has been shown to have a beneficial effect both in regard to the successful outcome of therapy, and to the reduction of the psychological aftermath of the illness. Ambroise Paré, in the sixteenth century, is credited with the aphorism that a doctor's lot was 'To cure seldom, to relieve often, and to comfort always'.

As anaesthetists, treating burned patients, we have the opportunity and the responsibility of following Paré's dictum.

\section{Acknowledgments}

The author wishes to thank Dr C. D. T. James (King's College Hospital) for his invaluable assistance in preparing this paper, and Dr R. M. Davies for his advice.

\section{References}

Allen, C.R. \& Slocum, H.C. (1952) The function of the anaesthesiologist in the management of the patient with extensive burns. Anaesthesiology, 13, 65.

Ballingall, Sir George (1833) Outlines of Military Surgery. Adam and Charles Black, Edinburgh and London.

Bernstein, N.R. (1963) Management of burnt children with the aid of hypnosis. Journal of Child Psychology, 4, 93.

BLACK, A.S. (1958) Anaesthesia and burns. Journal of the American Association of Nurse Anaesthetists, 26, 143.

Clarkson, P. \& Lawrie, R. (1946) The management of surgical resurfacing of burns. British Journal of Surgery, 33, 311.

CoHEN, S. (1970) The use of ketamine hydrochloride in burns. Transactions of the Third International Congress on Research in Burns, Hague, 1970, pp. 668-670. Huber, Berne Stuttgart and Vienna.

DAvidson, E.G. (1926) The prevention of toxaemia of burns. Treatment by tannic acid. American Journal of Surgery, $40,114$.

Dible, J.H. (1970) Napoleon's Surgeon. Heinemann Medical Books, London.

Dunbar, J. (1934) Review of the burns cases treated at the Glasgow Royal Infirmary during the past 100 years, with some observations on present day treatment. Glasgow Medical Journal, 122, 239.

Egyptian Medico-Religious Instruction Quoted from H. Sigrist. Primitive and Archaic Medicine, p. 278. Oxford University Press, 1967.

GoRDON, R.A. (1943) Intravenous novocaine for analgesia in burns. Canadian Medical Association Journal, 49, 478.

GlEadow, E.F. (1943) Trichlorethylene in the surgical ward (letter). Lancet, ii, 218.

Harbauer, M. Dtsch. Med. Weschr. 1963, 88, p. 1281. Quoted Editorial. British Medical Journal (1963), 11, 1350.

HowIE, C.C.M. (1970) Transactions of the Third International Congress on Research in Burns, Prague, 1970. Huber, Berne, Stuttgart and Vienna.

Humphrey, L. (1900) Manual of Nursing, Medical and Surgical. Charles Griffin, London.

Mitchell-Heggs, F. \& Walter, W.J. (1946) The German Hospital Centre at Abamo Terre. British Journal of Surgery, 33, 235.

New London Surgical Handbook (1836) Sherwood, Gilbert \& Piper, London.

Paré Ambroise. Apologia and Treatise. Dover Publications, New York, 1968.

Smith, G.B. \& Hollis, D. (1966) The use of dehydrobenzperidol and phenoperidine for repeated burns dressings. British Journal of Anaesthesia, 38, 471.

Thompson, J., Drewar, D.A. \& Ground, J.F. (1949) Trilene analgesia in paediatric patients. British Medical Journal, 11, 1449.

Van Swieten, Baron G. Commentaries on the Aphorisms of Boerhaave, Edinburgh, 1776. Quoted from W. P. Cockshott (1956). The history of the treatment of burns. Surgery, Gynaecology and Obstetrics, 102, 116.

VisSer, E.R. \& TARROW, A.B. (1959) Fluothane for multiple burn dressing. Anaesthesia and Analgesia, 38, 301.

WAKely, SIR C. (1944) Burns and their treatment. In: Surgery of Modern Warfare, Vol. I, pp. 171-191. Livingstone, Edinburgh.

WoODWARD, D.J. (1959) Emotional disturbances in burned children. British Medical Journal, 1, 1009. 